\title{
Investigation of Grooved Circular Jet Flow Experimentally and Using Computational Fluid Dynamics
}

\author{
A. T. INAN ${ }^{a, *}$, T. Sisman ${ }^{b}$ \\ ${ }^{a}$ Technology Faculty, Mechanical Engineering Department, Marmara University, Göztepe Kampüsü 34722 Istanbul, \\ Turkey \\ ${ }^{b}$ M.U. Vocational School Of Technical Sciences, Machinery And Metal Technology Dept., \\ Göztepe Kampüsü 34722 Istanbul, Turkey
}

\begin{abstract}
This study is the investigation of grooved circular jet flow experimentally and using computational fluid dynamics (CFD). Experimental studies were conducted by using straight circular and grooved circular tubes in a multi-purpose low-range subsonic wind tunnel. Single channel hot wire anemometer was used in turbulence measurements. Numerical studies for the solution of jet flow were performed through FLUENT program (ANSYS 14.5). Jet flow profiles at different velocities were formed by using the data generated at predetermined stations in the experiment room for the straight circular tubes and grooved circular tubes. After transferring the experimental data to Fluent, jet exit points of the circular tubes were placed in the quarter model to coincide with the initial coordinates of experimental room. CFD Calculations were done by implementing different velocities in the experimental room and the jet. Jet flow structures obtained from both computational and experimental calculations are shown in graphs and the data is presented in Tables. The obtained parameters are as follows: axis velocity $\left(U_{e}\right)$, root mean square velocity $\left(U_{\mathrm{rms}}\right)$, turbulence velocity $\left(U_{\mathrm{turb}}\right)$, jet half width $(b)$ and Reynolds numbers $\left(R e_{D}\right.$ and $\left.R e_{b}\right)$. These parameters were calculated with reference to jet radius and jet half width. Graphics formed by the generated non-dimensional data were compared to the previous studies.
\end{abstract}

DOI: $10.12693 /$ APhysPolA.127.1145

PACS: 47.27.wg, 67.85.-d, 66.30.je, 68.03.Kn, 47.80.Cb

\section{Introduction}

Jet flow, which is one of the basic flow types, has many applications in various fields of industry. Although there have been intensive studies on the structure of jet flow, there is no much information in public domain regarding the experimental and computational investigation of structure of jet and turbulence flow in inner grooved circular tubes. Since inner grooved circular tubes are also used as heat exchangers, it was thought that experimental and computational investigation of inner grooved circular tubes can be of beneficial in increasing the amount of knowledge about this type of flow.

The experimental work was carried out in a subsonic sucking wind tunnel having $32 \times 32 \mathrm{~cm}^{2}$ cross-section and $75 \mathrm{~cm}$ length. The turbulence density of the wind tunnel was between $0.4-0.7$. The measurements were performed by using a single channel hot-wire anemometer (HWA). Inner grooved copper tube was used for the circular jet flow. The air needed for jet flow was obtained through an air generator. Measurements were performed for different velocities [1].

Numerical analysis was conducted with respect to the points determined by experimental measurements and solved by the help of a program related to finite volume method. $U_{\text {rms }}$, dimensionless velocity distributions and jet expansion ratios were formed by transferring these points in to the graphical environment. The ob-

* corresponding author; e-mail: ainan@marmara.edu.tr

tained experimental and numerical data were compared to the data obtained from other circular jet flow measurements [1]. The comparison and evaluation of experimental and numerical data were conducted on the same graphics and tables.

The first study about the free jet flow developing with respect to the fluid environment was performed by Trupel in 1915 [2]. Reichardth in 1942, Corrsin in 1946 [3], Hinze and Zijnen in 1949 [4] and Albertson et al. in 1950 were all first researchers in the investigation of same subject [5]. They conducted a more detailed investigation with the help of a hot-wire anemometer. In 1961, Wygnanski and Fiedler demonstrated different appearances of the turbulence structures of the free jet and RMS variations of turbulence fluctuation values along the jet flow axis using hot-wire anemometer [6]. Davies, Fisher [7] and Bradshaw conducted similar studies in the same subject [8]. A similar study was also performed by Hussein and George [9] and this work was repeated by Taulbee using LDA (Laser Doppler Anemometry) [10]. The measurements showed that the spread of circular jet flow was slower than planar jet flow and self-similarity region took place at a distance of 50-70 D after the outlet of the nozzle. Turbulence profile measurements have started after the recognition of hot-wire anemometry method. Turbulence values for a circular free jet were measured by Corrsin [11] and other researchers. Wygnanski and Fiedler [6] performed same measurements for circular free jets using more advanced equipment. They showed that jet flow structures at the axis were in self-similarity form at a distance of $40 \mathrm{D}$ after the outlet of the nozzle. 
Corrsin and Uberoi [12] showed that the structure of jet flow profile started to deteriorate towards the developing turbulence region. They also showed that the jet flow depended on initial and boundary conditions. Jet half-width is the most common physical characteristics of the free jet. Jet half-width, $y_{h}$, is equal to half of the summation of axis velocity of the jet flow. Jet spread ratio, which is one of the other physical characteristics, is the ratio between jet half-width distance and the distance in the direction of jet flow [13].

Morris and Zaman (2010) investigated the characteristics of a symmetrical axis jet experimentally and numerically with the help of hot-wire anemometer and double component anemometer. In that study, they estimated the noise level using the velocity fluctuations obtained from measurements at the jet outlet and at the axis [14].

Sivakumar et al. measured the structure of circular jet flow by using a hot-wire anemometer having a CTA Unit. They studied potential core region of the circular jet flow. Reynolds Numbers between 4000-8000 were considered for the mean jet radius. The characteristics of the structure of the jet flow and velocity statistics were presented with respect to these values. In that study a compressor was used as a jet air generator and a hot-wire anemometer with a CTA Unit was used as measurement device [15].

Experimentally obtained $U_{e}, b, R e_{D}$ and $R e_{b}$ data for plain circular tube, with jet velocity of $20 \mathrm{~m} / \mathrm{s}$ and tunnel flow velocities of 0,5 and $10 \mathrm{~m} / \mathrm{s}$.

TABLE I

\begin{tabular}{c|c|c|c|c|c|c|c|c|c|c|c|c}
\hline \hline \multicolumn{3}{c|}{$D D_{03}\left(U_{j}=20 \mathrm{~m} / \mathrm{s}, U_{t}=0 \mathrm{~m} / \mathrm{s}\right)$} & \multicolumn{3}{c|}{$D D_{07}\left(U_{j}=20 \mathrm{~m} / \mathrm{s}, U_{t}=5 \mathrm{~m} / \mathrm{s}\right)$} & \multicolumn{3}{c}{$D D_{10}\left(U_{j}=20 \mathrm{~m} / \mathrm{s}, U_{t}=10 \mathrm{~m} / \mathrm{s}\right)$} \\
\hline$x / D$ & $U_{e}[\mathrm{~m} / \mathrm{s}]$ & $b[\mathrm{~m}]$ & $R e_{D}$ & $R e_{b}$ & $U_{e}[\mathrm{~m} / \mathrm{s}]$ & $b[\mathrm{~m}]$ & $R e_{D}$ & $R e_{b}$ & $U_{e}[\mathrm{~m} / \mathrm{s}]$ & $b[\mathrm{~m}]$ & $R e_{D}$ & $R e_{b}$ \\
\hline 0.3 & 23.390 & 0.007727 & 25625 & 12375 & 27.961 & 0.008825 & 30633 & 16896 & 27.003 & 0.006394 & 29584 & 11822 \\
12.5 & 10.467 & 0.010711 & 11467 & 7676 & 13.188 & 0.006711 & 14448 & 6060 & 15.312 & 0.005333 & 16775 & 5591 \\
31.2 & 5.528 & 0.016774 & 6056 & 6349 & 9.363 & 0.015286 & 10257 & 9800 & 13.380 & 0.010191 & 14658 & 9336 \\
50 & 3.450 & 0.013201 & 3779 & 3118 & 7.762 & 0.015525 & 8503 & 8251 & 12.248 & 0.010417 & 13418 & 8736
\end{tabular}

Experimentally obtained $U_{e}, b, R e_{D}$ and $R e_{b}$ data for inner grooved circular tube, with jet TABLE II flow velocity of $20 \mathrm{~m} / \mathrm{s}$ and tunnel flow velocities of 0,5 and $10 \mathrm{~m} / \mathrm{s}$.

\begin{tabular}{|c|c|c|c|c|c|c|c|c|c|c|c|c|}
\hline \multicolumn{5}{|c|}{$D D_{03}\left(U_{j}=20 \mathrm{~m} / \mathrm{s}, U_{t}=0 \mathrm{~m} / \mathrm{s}\right)$} & \multicolumn{4}{|c|}{$D D_{07}\left(U_{j}=20 \mathrm{~m} / \mathrm{s}, U_{t}=5 \mathrm{~m} / \mathrm{s}\right)$} & \multicolumn{4}{|c|}{$D D_{10}\left(U_{j}=20 \mathrm{~m} / \mathrm{s}, U_{t}=10 \mathrm{~m} / \mathrm{s}\right)$} \\
\hline$x / D$ & $U_{e}[\mathrm{~m} / \mathrm{s}]$ & $b[\mathrm{~m}]$ & $R e_{D}$ & $R e_{b}$ & $U_{e}[\mathrm{~m} / \mathrm{s}]$ & $b[\mathrm{~m}]$ & $R e_{D}$ & $R e_{b}$ & $U_{e}[\mathrm{~m} / \mathrm{s}]$ & $b[\mathrm{~m}]$ & $R e_{D}$ & $R e_{b}$ \\
\hline 0.3 & & & & & & & & & & & & \\
\hline 12 . & & & & & & & & & & & & 77 \\
\hline 31.2 & 4.066 & 0.01 & 4454 & 103 & 8.699 & & & & 12.46 & 36 & & 9208 \\
\hline 50 & 1.935 & 0.022913 & 2119 & 3035 & 7.086 & 0.020695 & 7763 & 1004 & 11.262 & 0.010872 & 12338 & 8383 \\
\hline
\end{tabular}

\section{Experimental method and measurement elements}

\subsection{Experimental method}

An inner grooved copper tube having $120 \mathrm{~cm}$ length and $16 \mathrm{~mm}$ inner diameter was used for the measurements of the jet flow. Features of inner grooved copper tube are given in Fig. 1 and the layout of experimental set-up is shown in Fig. 2.

Experimental work was conducted under three categories as follows:

1. For the flow analysis of experimental chamber, flow measurements were performed by sending the air into the chamber at different velocities $(5,10,20$, $25 \mathrm{~m} / \mathrm{s})$.

2. The measurements were performed at different velocities $(5,10,20,25 \mathrm{~m} / \mathrm{s})$ both for plain circular tubes and inner grooved circular tubes. During these measurements no air jet is sent to experimental chamber.

3. Both tunnel and jet were measured under different velocity conditions. In tunnel, mean velocity $u$, fluctuation velocity $u^{\prime}$ and root mean square $\mathrm{rms}$ values were measured.

The data obtained through measurements are presented in a graphical form in Fig. 3, 4 and 5. These values were employed in numerical calculations in order to

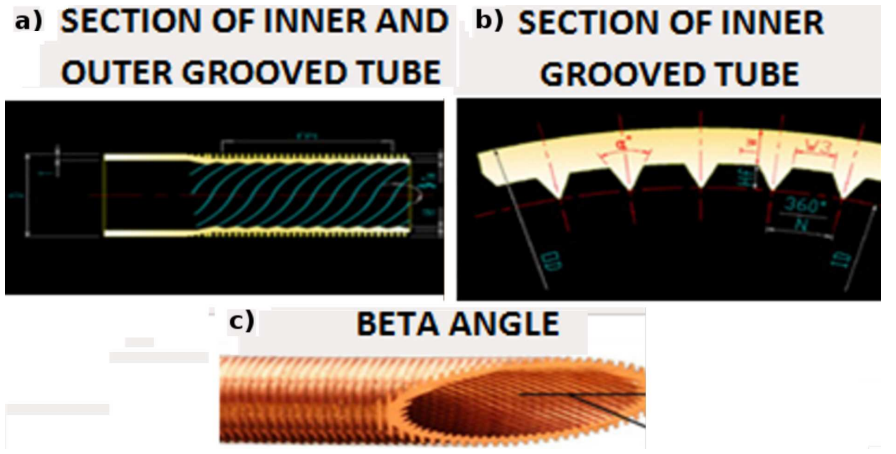

Fig. 1. Inner grooved circular tube. (a) Section of inner and outer grooved tube, (b) section of inner grooved tube [16], (c) beta angle.

find the velocity at the axis, jet half-width and Reynolds numbers. These parameters are presented in Table I and Table II.

Plain circular copper and inner grooved copper tube having $120 \mathrm{~cm}$ length with $16 \mathrm{~mm}$ inner diameter and $19 \mathrm{~mm}$ outer tube diameter were used for the jet flow measurements. First jet flow measurements conducted without tunnel flow and then jet flow experiments conducted by varying tunnel flow and jet flow outlet velocities.

The data obtained through measurements were employed for the graphical presentation of flow profiles. In addition, velocity changes which took place along the jet 


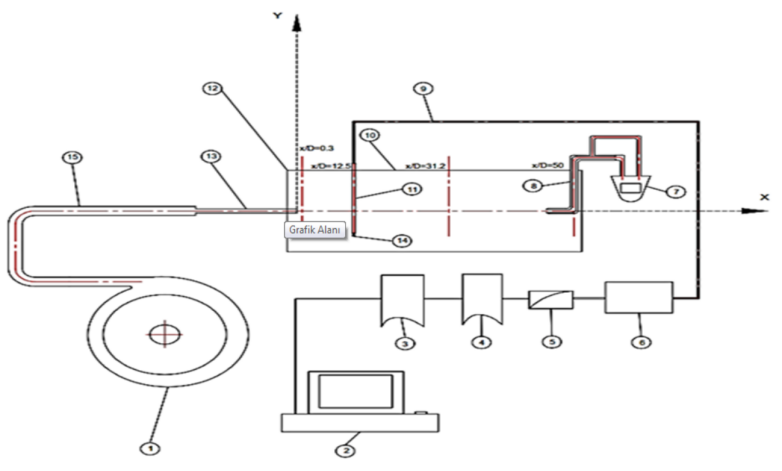

Fig. 2. Layout of experimental set-up: 1. jet air generator, 2. computer, 3. data analysis element, 4. time series, 5 . linearization, 6 . Wheatstone bridge and servo amplifier, 7. digital Pitot static tube screen, 8. Pitot tube, 9. coaxial cable, 10. experimental chamber, 11. probe support, 12. wind tunnel experimental chamber inlet, 13. jet tube element, 14. probe, 15 . tube connection element.
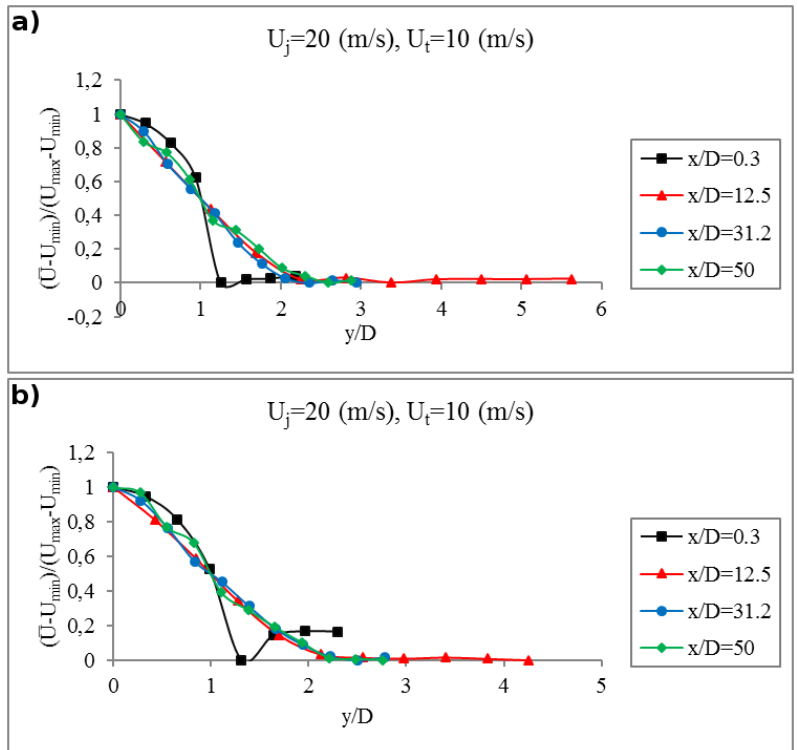

Fig. 3. Dimensionless velocity distributions for plain circular tube (a) and inner grooved circular tube (b), for tunnel velocity of $10 \mathrm{~m} / \mathrm{s}$ and jet velocity of $20 \mathrm{~m} / \mathrm{s}$.

axis and the ratios of jet beams were also presented in graphical form.

FLUENT analysis results are given for plain circular jet and inner grooved circular jet in Tables III and IV respectively. Values of axis velocity $U_{e}$, jet half-width $b$, jet diameter Reynolds number $R e_{D}$ and jet half-width Reynolds number $R e_{b}$ were considered in the measurement stations of $x / D=0.3, x / D=12.5, x / D=31.2$ and $x / D=50$, where experimental chamber velocities were 0,5 and $10 \mathrm{~m} / \mathrm{s}$ and jet velocity was $20 \mathrm{~m} / \mathrm{s}$.

\subsection{Numerical method}

In this section, jet flow was resolved by employing the CFD method. FLUENT program, which is a module of ANSYS 14.5, was used for this purpose. Jet flow in the

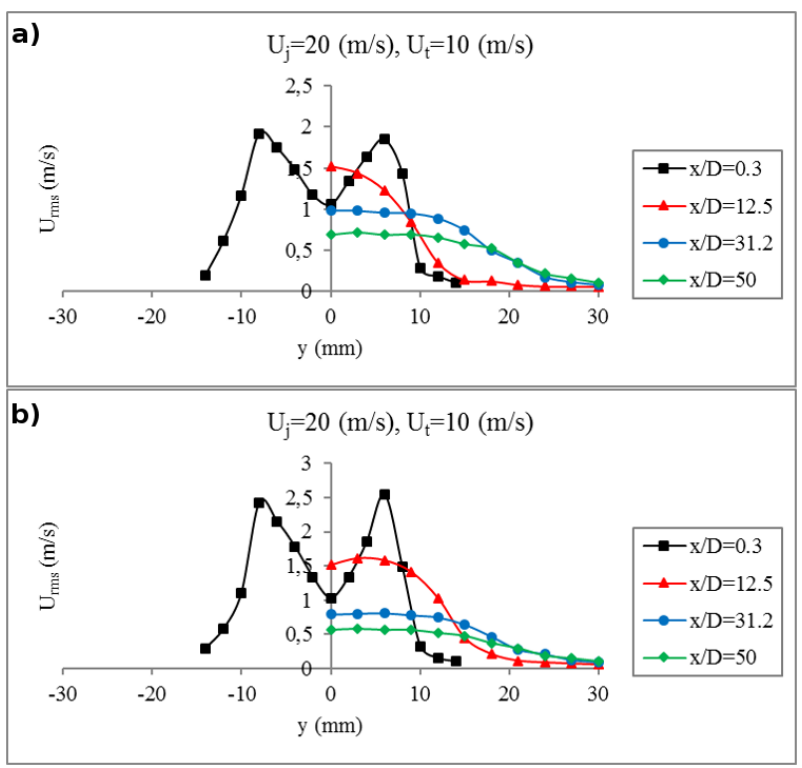

Fig. 4. $U_{\text {rms, }}$, velocity distributions for plain circular tube (a) and inner grooved circular tube (b), for tunnel velocity of $10 \mathrm{~m} / \mathrm{s}$ and jet velocity of $20 \mathrm{~m} / \mathrm{s}$.

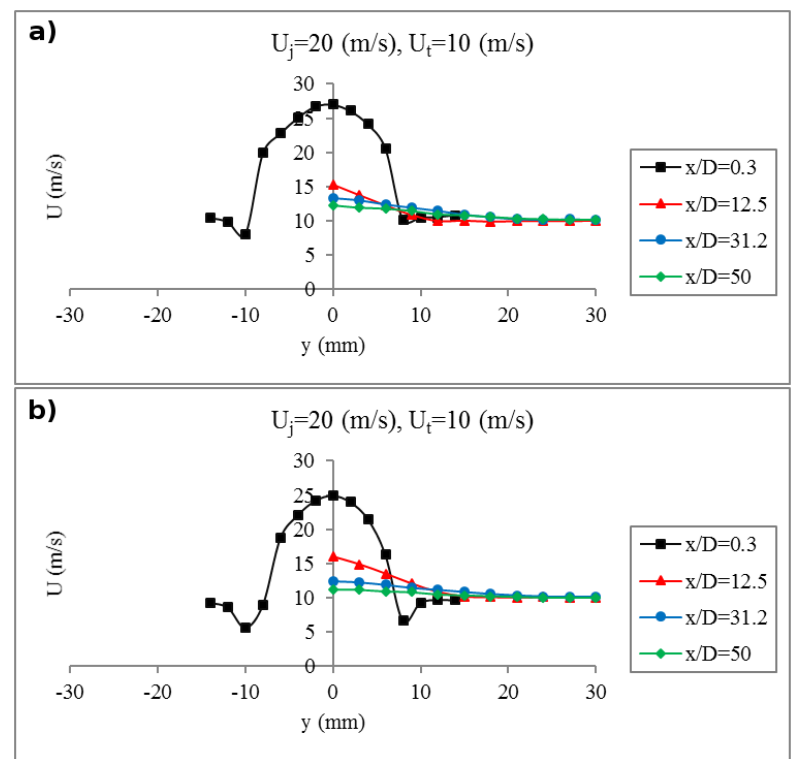

Fig. 5. Mean velocity distributions for plain circular tube (a) and inner grooved circular tube (b), for tunnel velocity of $10 \mathrm{~m} / \mathrm{s}$ and jet velocity of $20 \mathrm{~m} / \mathrm{s}$.

experimental chamber was modeled by using Solidworks and then transferred into the FLUENT. After the transfer; as in the experimental stages, outlet points of circular tube jet flow elements were settled into the quarter model of tunnel chamber with respect to the initial coordinates of experimental chamber. CFD calculations were conducted in two ways. Firstly, experiments were performed for plain circular jet flow in experimental chamber with no air flow present and then with different jet velocities. The results were given in Tables III and IV. After the measurements, the data were transferred into the graphical form and presented as graphs. 
Numerically (CFD) obtained $U_{e}, b, R e_{D}$ and $R e_{b}$ data for plain circular tube, with jet flow velocity of $20 \mathrm{~m} / \mathrm{s}$ and tunnel flow velocities of 0,5 and $10 \mathrm{~m} / \mathrm{s}$.

\begin{tabular}{c|c|c|c|c|c|c|c|c|c|c|c|c}
\hline \hline \multicolumn{3}{c|}{$D D_{03}\left(U_{j}=20 \mathrm{~m} / \mathrm{s}, U_{t}=0 \mathrm{~m} / \mathrm{s}\right)$} & \multicolumn{3}{c}{$D D_{07}\left(U_{j}=20 \mathrm{~m} / \mathrm{s}, U_{t}=5 \mathrm{~m} / \mathrm{s}\right)$} & \multicolumn{3}{c}{$D D_{10}\left(U_{j}=20 \mathrm{~m} / \mathrm{s}, U_{t}=10 \mathrm{~m} / \mathrm{s}\right)$} \\
\hline$x / D$ & $U_{e}[\mathrm{~m} / \mathrm{s}]$ & $b[\mathrm{~m}]$ & $R e_{D}$ & $R e_{b}$ & $U_{e}[\mathrm{~m} / \mathrm{s}]$ & $b[\mathrm{~m}]$ & $R e_{D}$ & $R e_{b}$ & $U_{e}[\mathrm{~m} / \mathrm{s}]$ & $b[\mathrm{~m}]$ & $R e_{D}$ & $R e_{b}$ \\
\hline 0.3 & 23.167 & 0.00833 & 25381 & 13214 & 23.2019 & 0.008282 & 25419 & 13157 & 23.2058 & 0.008226 & 25423 & 13071 \\
12.5 & 8.65239 & 0.017611 & 9479 & 10433 & 13.1485 & 0.015084 & 14405 & 13580 & 16.7806 & 0.013539 & 18384 & 15556 \\
31.2 & 3.93672 & 0.019941 & 4313 & 5375 & 9.72725 & 0.017725 & 10657 & 11806 & 14.7024 & 0.016906 & 16107 & 17019 \\
50 & 1.40914 & 0.020759 & 1543 & 2003 & 9.12352 & 0.020603 & 9995 & 12871 & 12.9212 & 0.019568 & 14156 & 17313
\end{tabular}

Numerically (CFD) obtained $U_{e}, b, R e_{D}$ and $R e_{b}$ data for inner grooved circular tube, with TABLE IV jet flow velocity of $20 \mathrm{~m} / \mathrm{s}$ and tunnel flow velocities of 0,5 and $10 \mathrm{~m} / \mathrm{s}$.

\begin{tabular}{|c|c|c|c|c|c|c|c|c|c|c|c|c|}
\hline \multicolumn{5}{|c|}{$D D_{03}\left(U_{j}=20 \mathrm{~m} / \mathrm{s}, U_{t}=0 \mathrm{~m} / \mathrm{s}\right)$} & \multicolumn{4}{|c|}{$D D_{07}\left(U_{j}=20 \mathrm{~m} / \mathrm{s}, U_{t}=5 \mathrm{~m} / \mathrm{s}\right)$} & \multicolumn{4}{|c|}{$D D_{10}\left(U_{j}=20 \mathrm{~m} / \mathrm{s}, U_{t}=10 \mathrm{~m} / \mathrm{s}\right)$} \\
\hline$x / D$ & $U_{e}[\mathrm{~m} / \mathrm{s}]$ & $b[\mathrm{~m}]$ & $R e_{D}$ & $R e_{b}$ & $U_{e}[\mathrm{~m} / \mathrm{s}]$ & $b[\mathrm{~m}]$ & $R e_{D}$ & $R e_{b}$ & $U_{e}[\mathrm{~m} / \mathrm{s}]$ & $b[\mathrm{~m}]$ & $R e_{D}$ & $R e_{b}$ \\
\hline 0.3 & & & & & & & & & & & & \\
\hline 12. & & & & & & & & & & & & \\
\hline 31.2 & & & 506 & & & & & & & & & \\
\hline 50 & 1.31957 & 0.020921 & 1445 & 1890 & 8.50842 & 0.019504 & 9321 & 11363 & 12.973 & 0.019073 & 14213 & 16942 \\
\hline
\end{tabular}

Recently finite elements method has become an indispensable tool for industrial engineering designs and analyses. Day by day bigger and more complex designs have been simulated by employing finite elements method. The widespread utilization of finite elements method has also induced the development of automatic mesh generation algorithms [17]. 84166 elements and 16235 nodes were obtained in the present numerical study. A view of the generated 3-D mesh is shown in Fig. 6.

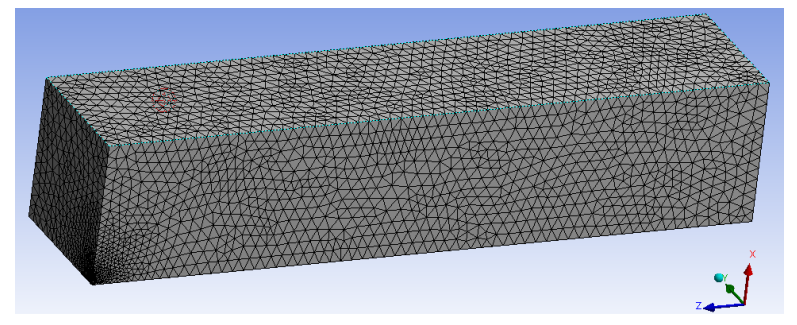

Fig. 6. A view of the generated 3-D mesh.

In this work, solid modelling and tetrahedral mesh structure were employed considering 3-D approach. Boundary conditions for this study are shown in Fig. 7.

Graphs of dimensionless velocity distributions and mean velocity distributions obtained from CFD analysis for plain circular jet and inner grooved circular jet are given in Fig. 8 and 9 respectively. The analysis was realized under the conditions of a tunnel velocity of $10 \mathrm{~m} / \mathrm{s}$ and a jet flow velocity of $20 \mathrm{~m} / \mathrm{s}$.

\section{Results and conclusion}

In this section, experimental and CFD data are compared to similar studies found in the literature. Firstly, measurements in the experimental chamber were conducted under the velocity conditions similar to jet flow experiments. From the measurements the turbulence densities were found to be between 0.4 and 0.7 [18]. These values were found to be suitable for the experimental work. In the experimental chamber four measurement stations $x / D=0.3, x / D=12.5, x / D=31.2$ and $x / D=50$ were determined for the measurements of

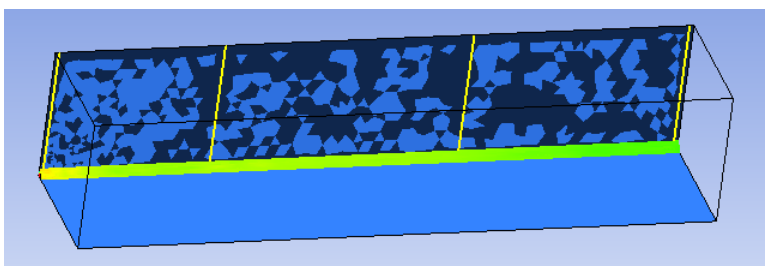

Fig. 7. Boundary conditions and structure of jet flow.

jet flow. Measurements were taken at vertical direction on predetermined distance points.

After the experimental chamber measurements, for plain circular tube and for inner grooved circular tube experimental investigations were carried out in tunnel chamber with no air flow present. Then measurements in the experimental chamber were performed for the plain circular tube and inner grooved tube jet flow under different jet velocities. The results are shown in Fig. 3, 4 and 5 . Finally jet flow was resolved by using a CFD program, called FLUENT, which is a module of ANSYS 14.5. Resolutions were performed in experimental chamber with no air flow present and with different flow velocities. Table III and Table IV show the measurement types resolved through CFD analysis. Again the data obtained from CFD modelling are presented in Fig. 8 and 9.

Axis velocity, jet half-width, jet diameter Reynolds number and jet half-width Reynolds number were calculated both for plain circular jet flow and inner grooved circular jet flows at predetermined measurement stations $(x / D=0.3, x / D=12.5, x / D=31.2$ and $x / D=50)$. The resultant values for the plain circular tube and inner grooved circular tube obtained from experimental work are given in the Tables I and II respectively. Similarly, the values for the plain circular tube and inner grooved circular tube obtained from CFD method are presented in Tables III and IV respectively.

As can be seen from the graphs, in experimental measurements the jet effect was observed starting from $x / D=0.3$ station to $x / D=50$ station for both plain circular jet and inner grooved circular jet. Computational 

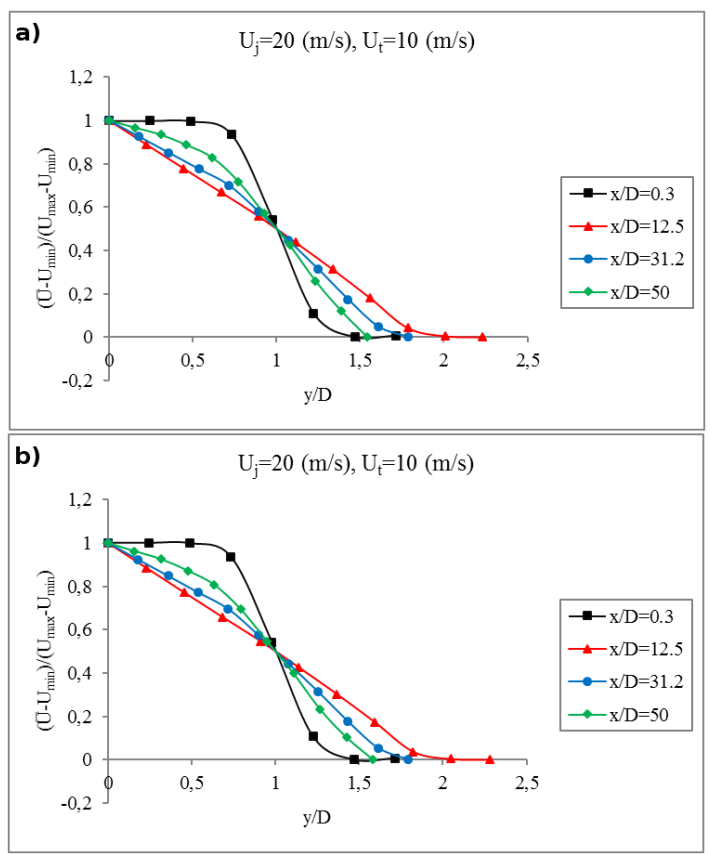

Fig. 8. Dimensionless velocity distributions obtained the from flow resolving program FLUENT, for plain circular jet (a) and inner grooved circular jet (b), for tunnel velocity of $10 \mathrm{~m} / \mathrm{s}$ and jet flow velocity of $20 \mathrm{~m} / \mathrm{s}$.
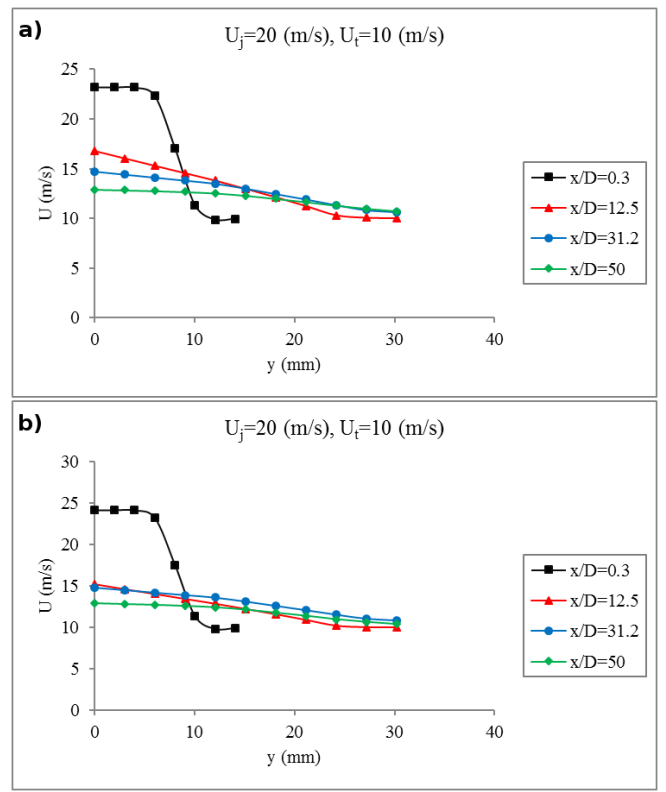

Fig. 9. Mean velocity distributions obtained from the flow resolving program FLUENT, for plain circular jet (a) and inner grooved circular jet (b), for tunnel velocity of $10 \mathrm{~m} / \mathrm{s}$ and jet flow velocity of $20 \mathrm{~m} / \mathrm{s}$.

fluid dynamics calculations also supported the idea that the jet effect tended to protect its presence in all measurement stations. The results of present investigation were supported by the works of [14] Morris and Zaman (2010) and [15] Sivakumar et al. (2012), since the structures of jet flows exhibited great similarities.
When the tunnel flow velocity was $10 \mathrm{~m} / \mathrm{s}$ and jet flow velocity was $20 \mathrm{~m} / \mathrm{s}$, the structure of the jet flow was found to be smooth in the $x / D=0.3, x / D=12.5$ and $x / D=31.2$ measurement stations. CFD calculations supported the above findings. A very slight turbulence was observed at the $x / D=50$ station. The least turbulence values were observed in this stage of the present work. It was observed that Reynolds numbers $R e_{D}$ and $R e_{b}$, which are calculated with respect to the diameter $D$ and jet half-width, became closer to each other when they progressed along with the $x / D$ direction. When they reached $x / D=50$ measurement station they were nearly of the same level with respect to the jet half-width, both for plain circular tube and inner grooved tube. This behavior depended on the increases in the tunnel flow velocities. It was observed that inner grooved jet flow structure deteriorated at shorter distances compared to the deterioration distance of plain circular jet flow structure. From the station $x / D=0.3$, it was observed that the structure of flow started to convert to the turbulence flow.

\section{References}

[1] T. Sisman, Master Thesis, Marmara University, Turkey 2013.

[2] J.O. Hinze, Turbulence, McGraw Hill, Newyork, USA, 1959.

[3] S. Corrsin, N.A.C.A., Wartime Report, 1946.

[4] J.O. Hinze, B.G. Van Der Hegge Zijnen, Appl. Sci. Res. 1, 435 (1949).

[5] M.L. Albertson, Y.B. Dai, R.A. Jensen, H. Rouse, Am. Soc. Civil Eng. 115, 639 (1950).

[6] I. Wygnanski, H. Fiedler, J. Fluid Mech. 38, 577 (1969).

[7] P.O.A.L. Davies, M.J. Fisher, Proc. Roy. Soc. A 280, 486 (1964).

[8] P. Bradshaw, Experimental Fluid Mechanics, Pergamon Press, Oxford, UK 1964.

[9] H.J. Hussein, W.K. George, rth. Symposium on Turbulent Shear Flows 2, 7 (1989).

[10] D.B. Taulbee, H. Hussein, S. Capp, 6th Symposium on Turbulent Shear Flows, Toulouse, France (1987).

[11] S. Corrsin, N.A.C.A., Wartime Report, 1942.

[12] S. Corrsin, M. Uberoi, N.A.C.A., TN 1865, 1949.

[13] W. Rodi, Ph.D. Thesis, Imperial College, London, 1972.

[14] P.J. Morris, K.B.M.Q. Zaman, J. Sound Vib. 329, 394 (2010).

[15] S. Sivakumar, R. Sangras, V. Raghavan, World Academy of Science, Engineering \& Technology 6, 119 (2012).

[16] http://www.sarkuysan.com/tr-TR/bakir-boru/88. aspx, 2011.

[17] H. Kayıkçı, Master Thesis, Master Thesis University of Marmara Istanbul, Turkey, 2006.

[18] A.T. Inan, Ph.D. Thesis, University of Marmara, Istanbul, Turkey, 2002. 